\title{
Empty Natural Kind Terms and Dry-Earth
}

\author{
Corine Besson \\ (forthcoming in Erkenntnis)
}

\begin{abstract}
This paper considers the problem of assigning meanings to empty natural kind terms. It does so in the context of the Twin-Earth externalist-internalist debate about whether the meanings of natural kind terms are individuated by the external physical environment of the speakers using these terms. The paper clarifies and outlines the different ways in which meanings could be assigned to empty natural kind terms. And it argues that externalists do not have the semantic resources to assign them meanings. The paper ends on a sceptical note concerning the fruitfulness of using the Twin-Earth setting in debates about the semantics of empty natural kind terms.
\end{abstract}

\section{Introduction: Emptiness and General Terms}

\section{I.1. Empty Natural kind Terms}

This paper is about the problem of assigning meanings to empty natural kind terms. Natural kind terms are terms such as 'water', 'horse' and 'tiger', and empty natural kind terms are terms such as 'phlogiston' and 'ether'. ${ }^{1}$ The paper addresses this issue in the context of the externalist-internalist debate about the meanings of natural kind terms - the debate that arose from Putnam's Twin-Earth thought-experiment (Putnam 1975). Externalists and internalists disagree about whether the meanings of natural kind terms are partly individuated by what exists in the external physical environment of the speakers using these terms. Externalists think that they are, and internalists think that they are not. One great difficulty for externalists concerns whether empty natural kind terms could be meaningful on their semantics: if the meanings of natural kind terms are partly individuated by what exists in the external physical environment, it seems that no meaning could be individuated when the relevant individuating factors do not exist in the environment. ${ }^{2}$ Many externalists have however argued that empty natural kind terms are meaningful on their semantics. ${ }^{3}$

\footnotetext{
${ }^{1}$ This paper only concerns natural kind terms in scientific or literal contexts (e.g. 'phlogiston'), where there is a genuine attempt to name a kind using a natural kind term; it does not discuss empty natural kind terms in fictional or mythical contexts (e.g. 'unicorn'). It is an open question whether these two sorts of contexts demand for different treatments of empty natural kind terms.

${ }^{2}$ This problem has been notably raised by Boghossian (1997) and Segal (2000).

${ }^{3}$ See for instance McLaughlin and Tye (1998), Sawyer (2003), Goldberg (2005) and Korman (2006).
} 
This paper sets out to clarify and outline the different ways in which meanings could be assigned to empty natural kind terms. And it argues that externalists, contrary to what many of them claim, do not have the semantic resources to assign meanings to such terms.

In debates about the semantics of empty expressions, proper names have received the most attention. They are the paradigm that models much of our theorising on emptiness. The aspect of the externalistinternalist debate that concerns empty natural kind terms is structurally similar to that between (say) direct referentialists and the neo-Fregeans (or descriptivists) about the meanings of empty proper names: neo-Fregeans argue that, because on a referentialist semantics the meaning of a proper name is partly individuated by its referent, referentialists cannot assign meanings to empty proper names (names without referents).

There are, however, many differences between proper names and natural kind terms. One aim of the paper is to highlight the similarities and differences between emptiness for natural kind terms and emptiness for proper names. For instance, unlike with empty proper names, discussions of empty natural kind terms have been mainly conducted in the setting of Twin-Earth style thoughtexperiments. This setting imposes its own constraints on possible semantic treatments of empty natural kind terms. The paper ends on a sceptical note concerning the fruitfulness of using the TwinEarth setting to debate the semantics of empty natural kind terms.

\section{I.2. Basic Semantic Considerations on Proper Names and Natural Kind Terms}

Natural kind terms are general terms, and proper names are singular terms. ${ }^{4}$ However, many philosophers think that natural kind terms share some of their fundamental semantic properties with such singular terms as proper names - paradigmatically being referring expressions. ${ }^{5}$ If natural kind terms are referring expressions they can then also be rigid designators, which many philosophers think they are. ${ }^{6}$ Here, natural kind terms will be treated as referring expressions.

\footnotetext{
${ }^{4}$ Some natural kind terms are mass nouns (e.g. 'water') and some are count nouns (e.g. 'tiger'). It has been argued that, unlike count nouns, mass nouns are not general terms (or at least not in all their uses). See Koslicki (1999) for discussion. For convenience, all natural kind terms are here treated as general terms; but nothing in the arguments below hangs on doing so.

${ }^{5}$ Notice here that some have argued (e.g. Devitt 2005) that general terms should be treated as expressions whose semantic function is merely apply or be true of objects, and not at all to refer.

${ }^{6}$ See for instance Kripke (1972), Soames (2002), Martì (2004), LaPorte (2006), and Besson (2010) for discussions.
} 
Also, the sorts of natural kind terms which are at issue here are natural kind nouns, that is, simple or single-word expressions for natural kinds. Descriptions, or otherwise complex expressions, for natural kinds, such as '(the) transparent liquid that falls as rain' or complex noun-phrases such as 'albino tiger' or 'yellow grass' are not discussed here. The rationale for focusing on simple expressions is as follows. It is first natural to assume that meaning is compositional, at least in the following way: complex expressions are meaningful insofar as their constituent expressions are. Thus complex terms for natural kinds are meaningful insofar as their constituent expressions are. In particular, complex empty terms for natural kinds are meaningful insofar as their constituent expressions are meaningful. This means that the fundamental question concerning emptiness is whether simple natural kind terms can be meaningful if empty. For example, although it might be the case that 'grass' is meaningless if empty, still 'yellow grass' might be meaningful if empty, provided that 'yellow' and 'grass' are meaningful. A world where there is grass and the colour yellow but no yellow grass, is a world where 'yellow grass' is meaningful.

It thus looks as if that insofar as there is a disagreement between externalists and internalists about complex expressions for natural kinds, it springs from a disagreement about how simple natural kind terms get to be meaningful. So the internalist-externalist debate is primarily about how to account for the meanings of single-word natural kind nouns. Henceforth, by 'natural kind terms' I will only refer to such nouns.

I said that both proper names and natural kind terms are referring expressions. Now, proper names are referring expressions that refer to objects. Roughly, a proper name succeeds in referring if there is a unique object that it picks out. Natural kind terms are referring expressions but it is not obvious that they refer to objects, and if they do, which sorts of objects. There are intuitively many sorts of things they could refer to, such as sets (e.g. intensions), properties, universals, kinds, tropes or Fregean concepts or what have you. Some of these are objects, others are not. I will take it that natural kind terms refer to natural kinds - without opting for a specific construal of natural kinds from the outset. But the consequences for the issue of emptiness of some construals of the referents of natural kind terms will be explored.

Also, the basic semantics of natural kind terms is more complicated than that of proper names: proper names only have the basic semantic function of referring to objects. Natural kind terms have two sorts of basic semantic functions: referring to kinds and, because they are general terms, applying to, or 
being true of, the samples of the kinds they refer to. For instance the term 'horse' refers to the kind horse and also applies to horses. ${ }^{7}$

These basic semantic considerations entail that emptiness is more complicated for natural kind terms than for proper names. Empty names are simply names that fail to refer to any objects. But natural kind terms can be empty in two ways: by not applying to any sample, and by not referring to any kind. Thus emptiness for natural kind terms can be defined in either of two ways:

(i) An empty natural kind term is a term that fails to apply to any sample.

(ii) An empty natural kind term is a term that fails to refer to any natural kind.

Consider (i). A natural kind term that fails to apply to any sample could still refer to a natural kind, i.e. an empty natural kind. For instance, suppose kinds are properties. It could be argued that if there were no horses (and never had been), 'horse' would refer to the empty kind horse. Another example is extinct kinds - kinds that had, but no longer have, samples: there are no dodos anymore, but arguably the kind dodo exists and 'dodo' refers to it. So, to be precise, here (i) will really be understood as (i*):

(i*) An empty natural kind term is a term that refers to an empty kind, where an empty kind is a kind that does not have any sample. ${ }^{8}$

Now consider (ii). On (ii) empty natural kind terms do not apply to samples, just as in (i*). However, (ii) is different from (i*) because (ii) is a case of reference failure, where the term does not even succeed in carrying out its referential role. For instance, one could argue that, if there were no horses in the external physical environment, 'horse' would refer to nothing whatsoever, not even an empty kind.

\footnotetext{
${ }^{7}$ Saying that natural kind terms both refer and apply is of course not saying that they are both singular terms and general terms. There are syntactic constraints on whether a word is a singular term or a general term: being a singular term is not sufficient for being a referring expression, and being a general term is not sufficient for being an expression that applies to things. Unlike singular terms, general terms are syntactically words that can form noun-phrases, be preceded in English by (in)definite articles, quantifiers and attributive adjectives. It is thus adequate to say that natural kind terms are general terms which have the semantic properties of both referring and applying. (But see again $\mathrm{n} .4$ for a possible caveat.)

${ }^{8}$ The natural way to understand the idea of a kind not having any sample is as not having any sample on Earth (or at the actual world) or at the Earth (or world) under consideration. A further question is whether a kind that does not have any sample on Earth (or at the actual world) could have any samples. There is no need to make a decision on this matter at this stage.
} 
Discussions of empty natural kind terms tend to overlook to the distinction between (i*) and (ii), and so it is not always clear what is meant by a natural kind term's being empty (or a natural kind concept being vacuous). But this distinction is crucial to understanding what is at issue with the problem of how to assign meanings to empty natural kind terms: (i*) and (ii) pose different threats to meaning. Intuitively, it is more problematic to assign a meaning to a (referring) term that fails to refer to anything whatsoever (as in (ii)) than it is to assign one to a referring term that refers to an empty entity (as in (ii*)).

In the following sections, I will first look at the different options available to externalists and internalists to assign meanings to empty natural kind terms. Given that externalism and internalism are claims about meaning, it is methodologically sound first to look at different things externalists and internalists might want to claim about the meanings of empty natural kind terms, and then to look at which construals of emptiness - $\left(i^{*}\right)$ or (ii) - can accommodate these claims. Of course, if no construal of emptiness can underwrite a given option on meaning, the latter will have to be rejected on this ground.

\section{I.3. Meaning}

I have characterised the key disagreement between externalists and internalists as concerning meaning - what it is for an expression to be meaningful. Although there is no neutral standpoint in this debate from which meaning can be characterised, the following clarification is in order. First, this much ought not to be too contentious: it is a minimal requirement on a semantic account of a language that it explains how its sentences can be assigned truth-values. Insofar as externalism and internalism are semantic accounts of some natural languages' expressions, their aim is to explain how these expressions contribute to truth-conditions. Thus here, we can take the meaning of a sentence to be what is said by that sentence, i.e. its truth-evaluable content, and the meaning of an expression to be the contribution it makes to truth-evaluable content.

Given this, externalists and internalists claim that the contribution natural kind terms make to truthevaluable content should be explained in different ways. In particular, they disagree about the interaction between meaning and reference, that is to say about the interaction between the contribution which a natural kind term makes to truth-conditions and which kind in the external physical environment that term refers to. Of course, this disagreement is also related to other considerations that are in play in questions about meaning, such as how the meaning of an expression connects to its use, how the epistemology of meaning works, whether meaning is transparent, etc. 
That is, such considerations may be in play in one's view of the relation between meaning and reference. But it is this relation that is at the heart of the externalist-internalist debate and on which I shall focus, in particular the question of whether empty natural kind terms (in the sense of (i*) or in the sense of (ii)) can make a contribution to truth-evaluable content.

Finally, let me stress here that I am treating the externalist-internalist debate as a debate about language - the meanings of a certain class of expressions. And indeed Putnam originally described the issue in these terms. However, the issue is now often stated as an issue concerning the contents of mental states (belief, knowledge, desire, fear, etc.), and semantic externalism is regarded as a special case of content externalism - as often issues about meaning are treated as a special case of more general issues about the mind. ${ }^{9}$

Thus many externalists and internalists cast their views in terms of 'belief state' and 'belief content' or 'representation' and 'content', rather than 'expression' and 'meaning', and make the assumption that one can straightforwardly extend claims about the meanings of expressions to claims about the contents of the mental states described by those expressions. For instance the original Putnamian question of whether the physical environment is extrinsic to the meanings of certain types of expressions is taken to translate directly the question of whether the physical environment is extrinsic to the contents of certain classes of mental representation. And considerations about meaning often get applied to mental content without further ado.

I do not discuss here whether it is apt to treat meaning and content on a par, or whether one could, say, be an externalist about meaning but an internalist about mental content. ${ }^{10} \mathrm{I}$ will assume that issues about emptiness can be stated equally as issues about language and issues about the mind. I focus on the linguistic issues about expressions and their meanings because by doing so I can highlight in a straightforward way how debates about natural kind terms connect with other types of expressions, such as proper names, and semantic notions such as reference and rigidity.

\footnotetext{
${ }^{9}$ See in particular Burge (1979), (1982), and (1986). The story seems to have gone like this: Putnam's externalist thesis was formulated as a thesis about natural kind terms. However, there still seemed to be something internalist about his view in that stereotypes (typical beliefs associated with a term) didn't seem to be externally determined. That is to say, Putnam (as far as his original paper goes) is not obviously an externalist about the mind. Burge notably extended externalism to mental states, which then became the focus of discussions of externalism. Thanks to Åsa Wikforss for discussion here.

${ }^{10}$ For instance Lewis (1979:143) seems to think that the fact that externalism is true of meaning does not entail that it is true of mental content.
} 
This is for the preliminaries. In section II, the issue of empty natural kind terms is set up within the externalist-internalist debate. Sections III-VIII assesses different strategies for assigning meanings to empty natural kind terms. The upshot is that externalists cannot assign them meanings. Finally, section VIII argues that Twin-Earth style thought-experiments are not fruitful settings in which to theorise about empty natural kind terms.

\section{Twin-Earth and Empty Natural Kind Terms}

\section{II.1. Twin-Earth and Dry-Earth}

The standard setting for the externalist-internalist debate about the meanings of natural kind terms is Putnam's Twin-Earth thought-experiment (Putnam 1975). Earth and Twin-Earth are two planets where the external physical environments are different only with respect to water: there is water $\left(\mathrm{H}_{2} \mathrm{O}\right)$ on Earth and there is twater $(\mathrm{XYZ})$ on Twin-Earth. The question here is whether 'water' would mean something different from what it actually does if it were introduced on Twin-Earth rather than Earth. Externalists claim that it would: the external physical environment partly individuates the meanings of natural kind terms, and so a difference in the environment with respect to water would entail a difference in the meaning of 'water'. Internalists claim that 'water' means the same on Earth and Twin-Earth: the environment plays no role in individuating the meanings of natural kind terms, and so a difference in the environment with respect to water between Earth and Twin-Earth would not entail a difference in the meaning of 'water'.

Now, given that natural kind terms are referring expressions (see I.2), the externalist-internalist debate can be stated more precisely: it is about whether the natural kinds which natural kind terms refer to in the external physical environment partly individuate their meanings. Externalists claim that they do, and internalists claim that they do not. ${ }^{12}$ The paradigmatic way to think of such natural kinds as existing in the external physical environment is that they do so by having samples: if the kind horse is exemplified (if there are horses), that kind exists in the external physical environment. Thus the

\footnotetext{
${ }^{11}$ The externalist-internalist debate at issue here concerns whether the natural kinds that are part of the external physical environment partly individuate the meanings of natural kind terms. There is another externalistinternalist debate about the meanings of natural kind terms, not at issue here, that concerns the extent to which speakers' understanding of natural kind terms is determined by social interactions. It is assumed here that these two debates are independent.

${ }^{12}$ Most internalists are not denying that natural kind terms are referring expressions, but merely that this semantic property is relevant to the individuation of their meanings. But see Chomsky (1995) for a contrasting opinion.
} 
central claim externalists seem to be making is that the meanings of natural kind terms are partly individuated by the exemplified natural kinds in the external physical environment that they refer to. Internalists deny any such individuation.

Externalist and internalist discussions of empty natural kind terms have recently focused on the socalled 'Dry-Earth scenario' (see Boghossian 1997). In Putnam's Twin-Earth scenario, the issue is whether 'water' would mean something different, if it referred to a different liquid with the same stereotype (on Twin-Earth) from that which it actually refers to (on Earth). In a Dry-Earth scenario, we compare Earth, where 'water' refers to water, and Dry-Earth, where (apparently at least) 'water' refers to nothing whatsoever - where there is (apparently) no natural kind that 'water' refers to. For instance, we can suppose that our near-intrinsic duplicates on Dry-Earth are the victims of the collective illusion that their use of 'water' refers to a liquid on Dry-Earth: they are under the illusion that there is a liquid that has the same stereotypical properties that water has on Earth (transparent, tasteless, thirst-quenching, etc.). However there is no such liquid or any relevantly similar one, where there is water.

The question now is whether 'water' would have meant something different from what it actually does if it had been introduced on Dry-Earth rather than Earth.

\section{II.2. The Meaning Options}

The following are the possible options for the meaning of 'water' on Dry-Earth. It is assumed here that 'water' on Earth is a meaningful natural kind term that refers to an exemplified kind:

(a) 'Water' is a meaningful natural kind term on Dry-Earth. It means the same as what 'water' means on Earth.

(b) 'Water' is a meaningful natural kind term on Dry-Earth. It means something different from what 'water' means on Earth.

(c) 'Water' is meaningless on Dry-Earth.

(d) 'Water' is meaningful on Dry-Earth. But it is not a natural kind term on Dry-Earth.

I discuss these four options in detail in the next five sections. Since the contrast between option (c) and the other options involves the notion of being a natural kind term, it will be clarified shortly. Also, assessing these options will involve deciding which construal of emptiness - (i*) and (ii) - are apt to underwrite them. 


\section{Option (a): Same Meaning}

Internalists who have discussed the Dry-Earth scenario have opted for option (a). ${ }^{13}$ It is the natural internalist option: if the external physical environment does not play any role in individuating the meanings of natural kind terms, then intuitively the meaning of 'water' is the same on Earth and DryEarth. The empty case does not pose a special difficulty and they can apply the same semantic machinery as in the nonempty case: take whatever earth you like - Earth, Twin-Earth or Dry-Earth 'water' means the same on those earths. It thus seems that internalists do not even have to go into the question of whether 'water' on Dry-Earth is empty in the sense of (i*) or (ii): whatever 'water' refers to, and whether or not it refers, that would be a feature of the external physical environment, and so not a factor that determines meanings.

So it seems that internalists should be untroubled by the issue of assigning a meaning to 'water' on Dry-Earth. I will not discuss this matter any further now, and move swiftly to externalism. However, I shall come back to internalism in section VII, and make some remarks in light of the discussion below which indicate that internalists are actually not free of trouble.

Internalists have in fact used the Dry-Earth scenario to argue that externalists cannot account for the meaning of 'water' on Dry-Earth, and, generally, for the meanings of empty natural kind terms (Boghossian 1997, Segal 2000). Segal, for instance, has argued that externalists face the following dilemma: they have either to go for option (c) or option (a). And neither is a possible option for externalists.

It is of course not possible for externalists to go for (a): saying that 'water' means the same on Earth and Dry-Earth would entail trivialising their account. This is because the external physical environment is clearly different in the relevant respect on Earth and Dry-Earth: there are no samples of water on Dry-Earth but there are on Earth. The problem is that if 'water' meant the same on Earth and Dry-Earth, it would mean the same on Twin-Earth and Dry-Earth. Indeed, the environment is the same on Earth and Dry-Earth but for the presence of samples of water, and equally, it is the same on Twin-Earth and Dry-Earth but for the presence of samples of twater: Dry-Earth lacks samples of both water and twater. And from the standpoint of Dry-Earth, there is nothing special about Earth as

\footnotetext{
${ }^{13}$ See Segal (2000), who endorses this option. See also Häggqvist \& Wikforss (2007) for discussion.
} 
opposed to Twin-Earth with respect to the word 'water'. But if 'water' means the same on Earth and Dry-Earth, and the same on Twin-Earth and Dry-Earth, then, by the transitivity of identity, it means the same on Earth and Twin-Earth. This is precisely what externalists want to deny. Thus externalists cannot say that 'water' means the same on Earth and Dry-Earth on pain of trivialising their account.

So externalists should say that 'water' means something different on Earth and Dry-Earth. A relevant difference in the external physical environment ought to entail a difference in meaning, and absence of the relevant kind is a relevant difference in the environment (see Sawyer 2003 on this point). Notice here that, as with internalism, we do not even have to go into the question of whether empty natural kind terms are empty in the sense of (i*) or in the sense of (ii): sameness of meaning is just not an option, whatever that might involve with respect to reference.

Consider for illustration an externalist account that looks like option (a) - the so-called 'source-based account', primarily applied to proper names (see Sainsbury 2001). On this account, the meaning of a proper name is individuated by the name-using practice it belongs to. This practice is itself partly individuated by the source of the use of the name (e.g. a baptism), but not by the object the name refers to (the thing baptised). This counts as an externalist view, since the name's meaning is individuated by external factors (e.g. the baptism and, the chain of communication through which the name is passed on), but not the sort of externalist view where the object referred to individuates the meaning of the name. This source-based account is meant to be neutral between empty and nonempty names: name-using practices for empty names work just like name-using practices for nonempty names. So, on this account, we have an explanation of how empty names might be meaningful.

However, this account is not externalist in the way required here. Consider again Dry-Earth. There is indeed a practice of the term 'water' on both Earth and Dry-Earth, although water exists on the former but does not on the latter. Now if, as the source-based account suggests, practices are not individuated by their objects (referents) - if they are neutral -, these practices will count as the same on Earth and Dry-Earth. Since the only difference between Earth and Dry-Earth is the referent of 'water', nothing can distinguish between these practices. If so, we have no grounds to assign a different meaning to 'water' on Earth and Dry-Earth. But externalists ought to assign them different meanings. 


\section{Options (c): No Meaning}

Option (c) is the second horn of Segal's dilemma for externalism. On this option, presumably 'water' is empty in the sense of (ii) - in the sense of failing to refer. ${ }^{14}$ If so, it is meaningless. Indeed, intuitively reference-failure poses a definitive threat to the possibility of meaning (see again section I.2).

Despite being described by internalists as a 'horn' of a dilemma, this option has a lot of be said for it. First, if 'water' is meaningless on Dry-Earth, it means something different on Earth and Dry-Earth: no trivialisation here. Secondly, it yields a consistent externalist position: if there is nothing in the environment that can individuate the meaning of a natural kind term, then the natural kind term means nothing. Indeed, it would seem very natural for externalists to say that 'water' is empty in the sense of (ii) on Dry-Earth. That is to say it refers to nothing whatsoever and thus is meaningless.

So why is option (c) thought to be bad? It is thought to be bad for pretty much the same reasons that are given against accounts of proper names that seem to entail that empty names are meaningless: we seem to understand these names, to be able to communicate using them, we assign truth-values to sentences containing them, etc. Given this, it is implausible to say that they are meaningless. It amounts to denying the phenomena.

Now, against this, I think that externalists could accept (c) as a consequence of their account and say that empty natural kind terms are meaningless on Dry-Earth. They could argue that this is something that they can live with, or that some separate account can be given for empty natural kind terms. Although this option has not been popular amongst externalists, it would be worth developing, and seeing how much of the phenomena described above could be accounted for without empty natural kind terms being meaningful. But this is for another paper. ${ }^{15}$

\footnotetext{
${ }^{14}$ There seems to be some confusion in the literature as to what the second horn of this dilemma is. For instance Korman (2006: 508) says that the problem is that 'the externalist contends that the concept dwater is necessarily vacuous'. But it would be question-begging for externalists to stipulate that there even is such a concept dwater. What is at issue here is not whether the concept is vacuous; it is whether there is such a concept at all that is expressed by 'water' on Dry-Earth. It is unclear why the former would be so much of a problem for externalists; and Segal (2000: 32) makes it very clear that it is the latter that is really problematic for them.

${ }^{15}$ Alternatively, externalists may say that they are not interested in giving a semantics for empty natural kind terms, but only for nonempty ones. They can agree that it would be desirable to have an account of empty natural kind terms, but argue that that is just not what they aim to do, and so need not have a tailor-made account for them. This reply is attractive, but I do not pursue it here. See also Korman (2006: 517-8) for discussion.
} 
Many externalists will still want to give an account according to which 'water' on Dry-Earth is meaningful and, generally, in which empty natural kind terms are meaningful. So externalists have to investigate options (b) and (d).

\section{Options (d): Not Natural Kind Terms}

This option is different from all the others in that it is not here assumed that 'water' is a natural kind term on Dry-Earth. This requires some background explanation. There is of course no agreement on what natural kind terms are: this is part of the issue. But the following should not be contentious as an initial externalist characterisation: a natural kind term is a semantically simple expression whose meaning is partly individuated by the natural kind it refers to (where a natural kind is an entity with a suitable (natural) unity - physical, chemical, biological, etc.). Thus, a semantically simple expression is an expression whose meaning is nondescriptive. And so something that makes it the case that a would-be natural kind term is not a natural kind term, or not a paradigmatic case of natural kind term, according to (d) is that its meaning is not semantically simple - it is descriptive. ${ }^{16}$

Thus, semantic complexity is the key behind option (d). It is assumed that 'water' on Earth is a natural kind term that succeeds in its function of having its meaning partly individuated by the exemplified kind it refers to: it is semantically simple - perhaps it is like a tag for a kind. But on DryEarth, there is no such kind to individuate the meaning and so the sort of meaning which the term has is different: it is semantically complex - perhaps it is given in terms of the stereotype associated with 'water'. ${ }^{17}$

Option (d) might look attractive because it meets many externalist desiderata: empty natural kind terms come out meaningful and the difference in the external physical environment between Earth and Dry-Earth is registered at the level of meaning: 'water' means something different on Earth and Dry-Earth. Typically, on this proposal, the empty case is treated in the same way as the case of

\footnotetext{
${ }^{16}$ I do not want to insist on labels here: it is simpler to say, especially if one wants to preserve an analogy with proper names, that natural kind terms are semantically simple and anything that is not semantically simple is not a natural kind term (Korman 2006). Alternatively, one might say that there are two sorts of natural kind terms: those (paradigmatic) that are semantically simple and those that are not. Note that in the literature antiindividualism (as opposed semantic externalism), the distinction is often stated in terms of atomic versus complex concepts. Here see. Boghossian (1997), Brown (2004), Goldberg (2005) and Korman (2006).

${ }^{17}$ See for instance Burge (1982), Sawyer (2003), Korman (2006) and Häggqvist \& Wikforss (2007) for discussion.
} 
natural kind terms that refer to motleys - several kinds - such as 'jade' (which refers to nephrite and jadeite). So we have a unifying treatment of both kinds of terms. ${ }^{18}$

But there are serious problems with this proposal. One is the very assumption that empty natural kind terms and natural kind terms that refer to motleys should have the same descriptive semantics. In the case of would-be natural kind terms that refer to motleys, there is a rationale for saying that their meanings should be given in terms of stereotypes. Stereotypes are supposed to be descriptions that are satisfied by all the members of the relevant kinds. But why think the same holds for 'water' on DryEarth? If we have too many referents for a term, we might want to give its meaning in terms of what these referents have in common. But when there is no referent, the move to descriptive meanings seems ad hoc.

It is possible that option (d) is really influenced by Russellian views on descriptive names, where there are two reasons why a name might really be a description: failure to refer and reference to more than one object. These correspond to the two ways Russellian descriptions fail to apply: lack of existence and lack of unicity. However, we need an argument as to why preferring a Russellian account is an attractive thing to do in this case. For instance few philosophers would find a Russellian account of empty proper names attractive. ${ }^{19}$

Also, in a strange way, this proposal is at once radically externalist, and yet very internalist. On the one hand, it is internalist, in that descriptivism is typically associated with internalism. And here all the standard critiques of descriptivism will apply (see of course Kripke 1972): lack of rigidity, unwanted necessities, unwanted apriorities, etc. So it looks like a big step back for externalism. At any rate, treating empty proper names as having a descriptive meaning has not been found to be an attractive option for referentialists. On the other hand, it is radically externalist because it means that whether an expression is descriptive or not depends on the external physical environment of speakers. Many will find this unattractive: it is one thing for externalists to say that the semantics of a term is determined by the environment, but quite another to say that which kind of semantics (simple or complex meaning) a term should be given (the term's metasemantics) is determined by the environment. $^{20}$

\footnotetext{
${ }^{18}$ See for instance Korman (2006), who treats them in the same way. See also McLaughlin \& Tye (1998).

${ }^{19}$ See Burge (1974) and Ludlow (2007) for contrasting views.

${ }^{20}$ See Häggqvist \& Wikforss (2007) for an excellent discussion of what they call 'foundational externalist accounts'. See also Boghossian (1997: 281) for objections to extending externalism in this way; see Ludlow (2003) for a defence of what he calls 'externalism about logical form'.
} 
This extreme form of externalism does not seem, as such, indefensible. ${ }^{21}$ For instance it might be the case that this is the right story for 'jade': it was intended to pick up a kind, i.e. to have a nondescriptive meaning, and then it was discovered that it referred to a motley, and so it was discovered that its meaning was really descriptive. But why, again, think that the same story would hold for 'water' on Dry-Earth? On Dry-Earth the problem is the reverse: there isn't too much by way of referents, but not enough.

So option (d) does not seem to be an attractive externalist option. Notice that since on this proposal 'water' on Dry-Earth would not even be a referring expression, we do not have to go into the issue of whether 'water' is empty in the sense of (i*) or (ii) again. This issue simply doesn't arise. Things change for the next, and last, option.

\section{Option (b): Meaning with Empty Referents}

If empty natural kind terms are neither meaningless nor descriptive, externalists are left with (b). How could this option work? The only plausible way to make it work is to assign a referent to 'water' on Dry-Earth. That is to say, it is to argue that 'water' on Dry-Earth is empty in the sense (i*): it refers to some empty entity and does not apply to any sample. Indeed, it would be very hard for externalists to claim that 'water' is empty in the sense of (ii): it is unclear how 'water' could be meaningful if it fails even to carry its referential role. Reference failure threatens the possibility of meaning for externalists. But if 'water' on Dry-Earth succeeds in carrying its referential role, there is some hope for it to be meaningful on an externalist semantics. On this proposal, externalists might be able to say that 'water' on Dry-Earth is indeed semantically simple.

Consider again the case of empty proper names It is a natural referentialist strategy to look for referents for empty names. On a referentialist account, if 'Vulcan' fails to refer, it is meaningless; however, if somehow it succeeds in carrying its referential role, it might be meaningful.

Before going into a detailed discussion of (b), two remarks are in order. First, it is worth emphasising that the following adequacy condition (Adequacy) should be met by an externalist account of this form:

\footnotetext{
${ }^{21}$ See Häggqvist \& Wikforss (2007) for arguments that it is.
} 
(Adequacy) A referent should be assigned to an empty natural kind term in a way that underwrites claims such as that 'water' means something different on Earth and Dry-Earth.

The assignment of a referent to 'water' on Dry-Earth should not merely serve to explain why 'water' is meaningful on Dry-Earth but also why it means something different on Earth and on Dry-Earth. If the latter cannot be done, externalism will again be trivialised.

Secondly, there are two sorts of empty entities that could be assigned to 'water' on Dry-Earth:

(A) 'Water' on Dry-Earth refers to the natural kind water, the same kind as on Earth, except that it is empty on Dry-Earth and nonempty on Earth.

(B) 'Water' on Dry-Earth refers to another (empty) natural kind than the (empty) kind water.

(A) entails that the same kind can exist on both planets, Earth and Dry-Earth, and can be empty on some planets. Alternatively, if Earth and Dry-Earth are construed as different possible worlds, as many philosophers do construe them, that means that the kind water can exist in different possible worlds, and be empty in some worlds. The latter construal would presumably demand that kinds be treated as abstract objects (e.g. properties or intensions), that can exist in different worlds. The former doesn't require this. The discussion that follows will be sensitive to the two ways of construing Earth and Dry-Earth: as different planets or as different possible worlds. I now give three independent objections against the proposal of assigning empty referents to empty natural kind terms so as to assign them meanings - as in option (i*). In doing so, I will consider the two different construals of $\left(i^{*}\right):(A)$ and $(B){ }^{22}$

\section{VI.1. No Suitable External Environment for Empty Kinds}

Consider the construal of emptiness in (i*). An empty kind does not have samples. As said in I.2., it is natural to think of kinds as existing in the external physical environment by having samples. If they do not have samples, it is unclear how empty kinds could exist in the external physical environment -

\footnotetext{
${ }^{22}$ It has been suggested that empty proper names refer to merely possible objects. I do not consider here assigning merely possible kinds to empty natural kind terms - there does not seem to be much difference between empty kinds and merely possible kinds. And even if there were one all the objections considered in this section would also apply.
} 
whichever sort of empty kind ((A) or (B)) is under consideration. But if so, it is equally unclear how, on an externalist semantics, the meaning of 'water' could be partly individuated by an empty kind on Dry-Earth; for it is not even clear how it could refer to that kind. This question is particularly pressing since externalists tend to appeal to a causal theory of reference to explain the relation between the meaning of a natural kind term and the kind it refers to (see Kripke 1972 and Putnam 1975): empty kinds are causally inert. The problem for externalists here is that if the meanings of natural kind terms are partly individuated by the external physical environment, that should hold too for empty natural kind terms - but empty kinds are not part of this environment, so they seem irrelevant to, or impotent in, the determination of meaning.

There is another problem with combining (b) and (i*). Consider Environment*, which is a sort of external environment which could accommodate empty kinds - perhaps Environment* is external but not physical or causal or concrete. Let us not worry too much about what Environment* exactly is, and how the causal theory of reference might apply here. Suppose that the meaning of 'water' on DryEarth is individuated by an empty kind that is part of Environment*. Now, presumably Environment* also exists on Earth. Indeed, by stipulation, Dry-Earth is just like Earth but for the presence of water. Also, presumably, Environment* exists on Twin-Earth, since Twin-Earth is just like Dry-Earth but for the presence of twater. But if Environment* is sufficient for assigning a meaning to 'water' on DryEarth, and if this environment exists on Earth, surely it must be sufficient for assigning a meaning to 'water' on Earth. But if so, it seems that we should assign the same meaning to 'water' both on Earth and Dry-Earth, for the meanings of natural kind terms are supposed to be partly individuated by some suitable external environment. Environment* is a suitable environment, but it is the same on these earths. That means that (Adequacy) is violated: even if there were a sense in which kinds are part of the external environment, that environment would be the same on Earth, Twin-Earth and Dry-Earth. And so it would be inadequate to help justify a difference of meaning between these earths.

\section{VI.2. Why Should Number Matter to Meaning?}

Suppose we opt for (A) and say that 'water' refers to the (empty) kind water on Dry-Earth; i.e. to the same kind as on Earth. Externalists could perhaps argue that 'water' means something different on those earths because water is nonempty on Earth but empty on Dry-Earth.

The problem here is that it is unclear why it should matter to the meaning of 'water' that it applies to samples on Earth but does not apply to any sample on Dry-Earth. Why should the number of samples matter to meaning, given that the referent is the same? 
Suppose 'water' applies to 100 samples of water on Earth, 10 on Earth* and 0 on Dry-Earth. Externalists would say that 'water' means the same on Earth and Earth*; in this case, the difference in the number of samples does not make a difference to meaning. But they would say that the meanings are different on Earth and Dry-Earth; in this case, the number of samples makes a difference to meaning. However, given that 'water' refers to water throughout, it is puzzling that the case in which there are 0 samples should be so dramatically different with respect to meaning from that in which there are 1 or more samples.

By way of analogy, consider empty proper names. Suppose there are empty names that refer to nothing whatsoever. For instance suppose 'Alice' refers to Alice on Earth but does not refer to anything on Earth*. The difference between these two earths is dramatic with respect to the name 'Alice': it is the difference between reference and reference failure. And it is natural to think (if one is a referentialist) that this difference matters greatly to the meaning of 'Alice'. If a name does not succeed in referring, its meaning is in trouble. But in our case we have nothing as dramatic: we have reference to the same kind - just a difference in the number of things it applies to. And it is unclear why this should matter to meaning.

So assigning the same referent to 'water' on Earth and Dry-Earth, except that it is empty on the latter violates (Adequacy): externalists cannot motivate a difference in meaning. If so, it looks like (Adequacy) is met only if 'water' refers to different kinds on Earth and Dry-Earth, i.e. it looks as if option (A) is not option for externalists. One more argument is given against it below.

\section{VI.3. No Empty Kind Can Do the Job}

\section{(VI.3.1) The (Empty) Kind Water}

Suppose again that 'water' refers to the (empty) kind water on Dry-Earth. The objection now is that this proposal is actually chauvinistic and unmotivated: it amounts to unjustifiably privileging the earthian standpoint in assigning a referent to 'water'. One observation made in section III was that from the standpoint of Dry-Earth, there is nothing special about Earth as opposed to Twin-Earth (say) regarding the word 'water'. This observation is relevant here. From the standpoint of Dry-Earth, there is nothing special about Earth as opposed to Twin-Earth (say) and so no more reason to say that 'water' on Dry-Earth refers to the (empty) kind water (which is nonempty on Earth) than there is to say that it refers to the (empty) kind twater (which is nonempty on Twin-Earth): there are no samples of water on Dry-Earth, but equally there are no samples of twater on Dry-Earth. If the (empty) kind 
water exists on Dry-Earth, the (empty) kind twater exists there too. And if so, it is arbitrary to say that 'water' refers to the former rather than to the latter.

From the standpoint of Dry-Earth all the earths that are just like Dry-Earth but for the fact that their term 'water' refers to a nonempty kind are on a par. We might be inclined to think that the referent of 'water' on Dry-Earth is water because our starting point in thinking about 'water' on Dry-Earth is Earth. But if we were Twin-Earthians, we would be inclined to say that 'water' refers to twater on Dry-Earth. We may have a privileged relation to the natural kind water, but the people on Dry-Earth do not, no more than they do have one with the natural kind twater. And here it is their perspective that matters because we are considering a case in which their natural kind term 'water' is empty. From their perspective choosing between the (empty) kind water and the (empty) kind twater is arbitrary.

In particular, there is nothing like what David Lewis has called a 'best candidate' to be the referent of 'water' on Dry-Earth, and no referent seems to be the 'reference magnet' for 'water' (Lewis 1983, 1984). Something is a reference magnet for a term if it is the best thing that fits the use of the term by speakers and if it is the most natural thing (on some metaphysical scale) that fits this use. Neither empty water nor empty twater fits (Dry-Earthian) use better than the other (if for instance use is determined by the associated stereotype, then the uses are relevantly similar); and neither is more eligible than the other (they are equally natural).

The upshot here is a familiar one in discussions of reference to empty entities: there are too many candidates and it would be arbitrary to select one.

So the option (A) of saying that 'water' on Dry-Earth refers to the empty kind water is, again, unsustainable. Thus externalists are left with the following possibility: the natural kind term 'water' means something different on Earth and Dry-Earth (i.e. option (b) of section II.2) because it refers to different kinds on Earth and Dry-Earth. On Dry-Earth it refers to an empty natural kind (i.e. option (i*) of section I.2) which is not water (option (B) of the beginning of this section).

\section{(VI.3.2) Native Empty Kind}

Suppose 'water' on Dry-Earth refers to an empty kind which is neither the (empty) kind water nor the (empty) kind twater (etc.) - a native empty kind, call it 'dwater'. Going native might help meeting 
(Adequacy): if 'water' refers to a different kind on Earth and Dry-Earth, its meaning can be different on these earths. It might also help with the issue of eliciting a unique referent for 'water'.

Unfortunately, appealing to native kinds will not help. One problem with 'water' referring to dwater on Dry-Earth is that it is unclear what that kind would be - e.g. what its molecular structure would be. If identity-conditions for dwater cannot be given, many kinds might count as dwater. ${ }^{23}$ How are we to choose? Another problem concerns whether the kinds water and twater also exist on Dry-Earth. That is, if dwater exists there, then presumably the (empty) kinds water and twater exist too. But if they exist on Dry-Earth, dwater would be no more salient than they are in Dry-Earth's external physical environment (or any Environment*). In particular, dwater would not be a best candidate for reference or a reference magnet for 'water'. It would thus be arbitrary to assign 'water' to dwater on Dry-Earth.

Now, externalists could perhaps argue that empty water and empty twater (and all the other relevant empty kinds) should be barred from Dry-Earth. The only non ad hoc way to do so is to stipulate that natural kinds cannot exist empty: they only exist when they have samples. But if that is so, dwater does not exist either, and so 'water' fails to refer on Dry-Earth.

Another possibility, but an ad hoc one, would be to say that kinds are planet-bound entities - or, if we consider Earth and Twin-Earth as two possible worlds, kinds are world-bound entities. Thus, dwater only exists on Dry-Earth, (empty) water only exists on Earth, etc. This option is definitely implausible if Earth and Twin-Earth are thought of as different planets. And if earth and Twin-Earth are thought of as different possible worlds, it also rules out many construals of natural kinds - for instance as properties or intensions. That would also not yet answer the problem of giving identity-conditions for dwater. So nativity is no help.

\section{(VI.3.3) Empty Intension/Property}

Consider the following proposal. Given that natural kind terms refer to kinds and apply to samples, one might think of these samples as forming the extension of the natural kind - where an extension is just a set. In this way a natural kind term could in some way be associated with the extension of the kind it refers to, where that extension is the set of the instances the term applies to. The term 'water' on Dry-Earth does not apply to any samples; that is to say, the extension associated with it is empty. Now, it is widely accepted by philosophers that the empty extension exists: it is just the empty set. So

\footnotetext{
${ }^{23}$ This argument is similar to the more extended one offered by Kripke in his (1972) for the claim that there could not be unicorns.
} 
a natural suggestion here would be to take the empty extension to be the relevant empty entity to which 'water' refers on Dry-Earth. Since there is only one empty set, the problem of there being too many candidates for the reference of 'water' on Dry-Earth would be avoided: the empty kind is the empty set.

Something similar has been suggested for empty proper names - that they refer to the empty set. ${ }^{24}$ One consequence of this view (sometimes attributed to Frege) is that both 'Vulcan' and 'Atlantis' (say) refer to the empty set. Now, the obvious problem here is that, intuitively, if they refer at all, these names refer to different things. A similar problem will be raised below for empty natural kind terms.

Now, one possible proposal would be to say that in general any natural kind that is referred to by natural a kind term should be identified with the extension associated with that term, not just the extension of empty natural kind terms. However, this would not do: extensions simpliciter would be inadequate as the referents of natural kind terms: extensions have their members essentially, which means that 'water' on Earth has (or refers to) a different extension whenever the number of parcels of water is different. That means that the referents of 'water' are different at different times. If, further, the meaning of 'water' is partly individuated by the kind in external physical environment which it refers to, the meaning of 'water' is also different at different times. This is not an attractive view. So if set-theoretic entities are going to be taken seriously at all as construals of natural kinds, the entities considered should be intensions.

Intensions are functions from worlds to extensions, and so they are better candidates than mere extensions to be the referents of natural kind terms; the problem of variation in extension is avoided: an intension is the same at all times and possible worlds. ${ }^{25}$ On Earth 'water' refers to the intension which assigns the set of parcels of water in all worlds; on Dry-Earth 'water' refers to the empty intension - which assigns the empty set to 'water' in all worlds. Thus 'water' on Earth and 'water' on Dry-Earth refer to different intensions. And so intensions might help externalists meet (Adequacy) the requirement that 'water' means something different on Earth and Dry-Earth.

\footnotetext{
${ }^{24}$ See Evans (1982: 32-32) for discussion. In this passage Evans considers a way in which a Fregean semantics could handle empty names: he considers replacing the distinction sense-reference by that of sense-semantic value and to identify semantic values with sets, the empty set in the case of empty proper names.

${ }^{25} \mathrm{I}$ assume here that intensions are total functions - i.e. exist in all possible times and worlds. They could also be construed as partial functions that are not defined for instance in all worlds - e.g. in worlds in which there are no samples of the relevant kind. I do not pursue these suggestions here, which would not make a substantive difference to the discussion.
} 
On this proposal, whether restricted to empty natural kind terms or extended to all natural kind terms, just as 'Vulcan' and 'Atlantis' both refer to the empty extension, 'water' and 'phlogiston' (say) on Dry-Earth both refer to the empty intension (supposing that 'phlogiston' is empty on Dry-Earth). This sort of proposal has for instance been made by Goldberg $(2005,159 \mathrm{ff}$.), who thinks that empty natural kind terms refer to the empty extension. A similar proposal has been made by Stoneham (1999), who argues that empty natural kind terms refer to the empty property of being identical with nothing.

One problem with this proposal is the same as that already raised for empty proper names: if 'water' and 'phlogiston' refer at all, they intuitively refer to different things. For instance, intuitively, it is not true that water $=$ phlogiston or that whatever is water is phlogiston.

But there is a greater difficulty here. One well-known challenge for externalists concerns illusion of sameness of meaning. In the Earth/Twin-Earth case, speakers of both earths may enjoy the following kind of illusion: 'water' means something different on Earth and Twin-Earth, but the meanings are so similar that speakers might wrongly think they are the same - the difference of meaning might even not be accessible to them. This of course points to the problem of whether externalism is compatible with privileged access. ${ }^{26}$ Externalists can explain why this illusion occurs by appealing to the fact that the stereotypes associated with 'water' on Earth and Twin-Earth are (or at least seem to be) the same. This is because what is labelled 'water' on both Earth and Twin-Earth has the same (or indistinguishable) superficial properties - it looks the same, tastes the same, behaves in the same way, etc.

If 'water' and 'phlogiston' refer to the same intension on Dry-Earth, externalists are now faced with a problem of illusion of difference of meaning. Although 'water' and 'phlogiston' seem to have different meanings to the speakers of Dry-Earth, externalists should say that they actually have the same meaning: meaning is partly individuated by the external (physical) environment, and the relevant environment is the same for 'water' and 'phlogiston' - they both refer to the empty intension/property. Now the illusion of difference of meaning is much more problematic for externalists than that of sameness of meaning. The problem is that they cannot appeal to the stereotypes associated with 'water' and 'phlogiston' to explain the illusion. The associated stereotypes are different, but this cannot be explained in terms of a difference in the superficial properties of water and phlogiston: these properties are the same - in the relevant sense, water and

\footnotetext{
${ }^{26}$ See McKinsey (1991), who first raised this issue.
} 
phlogiston behave in the same way on Dry-Earth, if they both refer to the empty intension. Thus an explanation of the illusion of difference in meaning in terms of a difference in superficial properties is not available here.

Some externalists have suggested that although 'water' and 'phlogiston' share referents, their meanings are nonetheless different: so there is no illusion here. For instance, Goldberg $(2005,158)$ wants to explain this difference in terms of a difference in functional roles, where these are not externally determined. On his version of externalism, referential intentions aside, the external environment is necessary to determine meaning, but it is not sufficient.

The first thing to note with this suggestion is that it constitutes a substantive concession to internalism: it is acknowledging narrow content as a component of meaning. Secondly, what is the relation between functional role and reference here? Consider 'water' on Earth and suppose we think of narrow content roughly in terms of stereotypes associated with expressions. In this case there is a relation between narrow content and reference: the referent satisfies the stereotype. Perhaps we can even think of narrow content in terms of character or mode of presentation. But what is the relation between the stereotype associated with 'water' on Dry-Earth and its putative referent? The problem here is that it really is unclear how referents connect with functional roles, indeed, whether they are at all related. As a result it feels as if the externalist is really assigning a referent to 'water' for the sake of avoiding reference failure, and that this assignment is again ad hoc. Thirdly, if functional roles can be appealed to for empty natural kind terms, it would seem that they can also be appealed to for nonempty natural kind terms: nonempty natural kind terms too have functional roles. (Just like, as argued in VI.2, if Environment* can be appealed to on Dry-Earth, it can be appealed to on Earth.) If so, it would make matters simpler to always identify the meanings of natural kind terms with functional roles. But externalists cannot do this, since it would amount to violating (Adequacy). Lastly, what are functional roles, really, and, in particular, are they hospitable to the view that natural kind terms are semantically simple? If not, then why not go for option (d) after all, which does not require us to postulate idle referents? So at least we would need an explanation of how 'water' is still semantically simple on this view.

Assigning the empty intension or the empty property to empty natural kind terms creates more problems than it solves. And so it remains unclear how externalists could assign referents to empty natural kind terms - as stated in $\left(i^{*}\right)$. 


\section{A Diagnosis}

Many externalists want to assign meanings to empty natural kind terms. They should do so in a way that meets (Adequacy) and that underwrites the claim that the environment partly individuates their meanings: since the external physical environments are different on Earth and Dry-Earth regarding water, 'water' should be assigned different meanings. After close examination, it looks as if the challenge is still in place. In particular, it appears that no empty kind is a suitable referent for 'water' on Dry-Earth - whether empty water, empty twater, dwater, the empty extension/intension or the empty property. But assigning empty referents to empty natural kind terms - option (b) - was really the only plausible option left to externalists who want to assign meanings to empty natural kind terms.

In section III, I suggested that, intuitively, internalists can assign a meaning to 'water' on Dry-Earth that meaning would be the same as on Earth and Twin-Earth. Indeed I suggested that an advantage of their view is that they do not have to worry about the empty case. In light of the foregoing discussion of externalism, this claim should now be qualified.

Thus consider again the two construals of emptiness for natural kind terms (i*) and (ii), of section I.2. Consider (ii) first: it is perhaps true that, given the spirit of internalism, reference failure does not pose an immediate threat to the possibility of meaning. And some internalists might be tempted to say that 'water' is meaningful but fails to refer to anything whatsoever on Dry-Earth. But this is a road which not all of them will want to take, since it might involve trouble with truth and logic, if not with meaning: for instance it might involve giving up bivalence, if sentences containing natural kind terms turn out to be truth-valueless. That is to say it is unclear how these terms would contribute to truthconditions. It might alternatively involve adopting a free logic, if meaningful empty natural kind terms are admitted in the language. ${ }^{27}$ So internalists should at least make these commitments explicit. This is to say that on an internalist semantics there might not be a problem of meaning for empty expressions, but there are definitely problems down the line, when truth and logic are considered.

Consider $\left(i^{*}\right)$ - reference to empty kinds. Like externalists, internalists cannot assign an empty referent to 'water' on Dry-Earth. Now, (Adequacy) is of course not an issue for them - since they think that 'water' means the same on Earth and Dry-Earth. But even if internalists do not think that the meanings of natural kind terms are partly individuated by their referent, they would still have to

\footnotetext{
${ }^{27}$ See Besson (2009) for discussion here.
} 
explain how one can pick out a unique referent for 'water' on Dry-Earth. In this, they will face the same problems as externalists: there will be too many candidates and no reason to pick one in particular. They can assign referents to empty natural kind terms no more than the externalists can. Indeed, the discussion in section VI points to general problems with the very idea of bringing in empty entities in the context of Twin-Earth style thought-experiments. ${ }^{28}$

Finally, perhaps empty natural kind terms do not pose a specific threat to internalists. But of course a great challenge for them is to explain what, quite generally, individuates the meanings of natural kind terms, if not the external physical environment. This might be thought to be a far more overarching threat than that of natural kind terms.

\section{Emptiness and the Twin-Earth Setting}

An issue worth addressing in closing is the role played by the Twin/Dry-Earth setting in the argument that no meaning can be assigned to 'water' on dry-Earth on an externalist semantics; for it seems that it plays a substantive role.

For one thing, we cannot be chauvinistic when we think of the meaning of 'water' in the setting of Dry-Earth. The natural kind terms whose meanings are at issue are assigned their basic semantic properties there, and not on Earth. One consequence is that we cannot presume that Earth has any privileged status with respect to Dry-Earth or any other earth: in particular we cannot presume that Dry-Earth is just like Earth but for the fact that the (earthian) natural kind water is empty; it would be a bit like presuming that Twin-Earth is just like Earth but for the fact that the kind water has a different molecular structure. It is impossible that the kind water has a different molecular structure from the one it actually has.

Another consequence is that not only Earth, but all the other earths that have the same relation of similarity with Dry-Earth have to be taken into account. Any choice is arbitrary. However, there is

\footnotetext{
${ }^{28}$ Internalists could also argue that 'water' on Dry-Earth does not refer to a natural kind at all, but to a property that is determined by/identical with the (superficial) properties that water, twater, etc. have in common. In this case there would not be too many candidates for the reference of 'water', but just one. Thus 'water' on Earth would refer to the kind water and 'water' on Dry-Earth would refer to this property. This, even by internalist standards, would entail that 'water' on Dry-Earth is not at all the same kind of expression as on Earth, and it would invalidate the claim that internalists do not have to give a special treatment for empty expressions. Thanks to Åsa Wikforss for discussion here.
} 
something unintuitive about having to consider all these candidates for reference when what we really want to do is to think of a counterfactual situation in which our term 'water' is empty. It seems that what we want to do is, for want of a better expression, something 'closer to home'.

Secondly, and relatedly, in the standard Twin-Earth case, we do not have to worry too much about whether the (empty) kind twater (say) exists on Earth. This is because the kind water is salient in Earth's environment, as there are sample of water on Earth: there is a reference-magnet. But when the kind water is not salient because it is empty, the plethora of empty kinds (empty twater, dwater, etc.) that clutter Earth are relevant when assigning a referent to 'water': there is no longer a referent magnet, and no non-arbitrary choice to be made between empty referents. So those who want to assign empty kinds to empty natural kind terms should at least say that kinds, even empty ones, are planet-bound (or world-bound) entities. But that is not a very intuitive view to have, and it still does not address how such entities might be referred to.

Lastly, a more open-ended point: it is unclear that we have the intuition that 'water' means something different on Earth and Dry-Earth. That is to say, it is unclear that we have the same sort of intuition that we have in the standard Twin-Earth case. Indeed suppose 'water' is empty on Earth (in the sense of (i*) or (ii)). Do we really have the intuition that 'water' would then mean something different than it actually does? At least the intuition is not as clear cut as in the Twin-Earth case: you might think that 'water' would be meaningful, but perhaps not that its meaning would be different. If so, it seems that the intuition of difference of meaning in the standard Twin-Earth case depends crucially on the different sorts of samples that we find on Earth and Twin-Earth - they have different molecular structures. But when we do not have samples as in the Dry-Earth case, it is not clear that we have the intuition of difference of meaning. Of course, the threat of trivialisation is looming here, so externalists have to stipulate a difference of meaning, without being able to ground it in a difference in samples. But if there is an asymmetry of intuitions between the Twin-Earth and the Dry-Earth case, it might equally be suggested that the setting of Dry-Earth does not help clarifying the semantic facts because it does not obviously generate strong semantic intuitions one way or the other.

These considerations suggest that discussions of empty natural kind terms are not best served by the Twin-Earth setting. In particular, Dry-Earth does not seem a fruitful context in which to consider the semantics of 'water'. However, it might be thought that since Twin-Earth is a fruitful context in which to think about nonempty natural kind terms (such as 'water' on Earth and 'water' on Twin-Earth) it is equally fruitful to think about empty ones. It might also be thought that because Dry-Earth is not a 
fruitful context, Twin-Earth is not a fruitful one either. This would be a bit quick. For instance, it is not obvious that if we reject the Twin-Earth setting for empty natural kind terms we have to reject it across the board. Perhaps empty natural kind terms are too unlike nonempty ones: perhaps they are not really natural kind terms, perhaps they have to be theorised in a different way from nonempty ones. But if we think that Dry-Earth is the right context in which to think about emptiness for natural kind terms, there is little prospect for externalists to endow empty natural kind terms with meanings; and there is little prospect for assigning empty referents to natural kind terms.

These considerations further lead to the following worry, which is a worry of circularity. A semantic proposal (e.g. internalism, externalism) is made about a given class of expressions (e.g. natural kind terms) using a certain sort of argument (e.g. Twin-Earth). This sort of argument is supposed to help us find out about the semantics of that class of expression. It is then supposed that the same sort of argument (e.g. Dry-Earth) can be used to find out about other expressions (empty natural kind terms) which for some reason ought to be given the same kind of semantics (e.g. a natural kind term semantics). But this itself presupposes that we have a good antecedent grip on what really is required to be a member of that class of expressions, of what it is to be a natural kind term. But this is precisely what the arguments (e.g. Twin-Earth, Dry-Earth) are supposed to help us find out. So at least participants in the debate should be clearer about what the methodology is supposed to be here.

\section{Conclusion}

I have considered ways in which externalists and internalists can assign meanings to empty natural kind terms, in the context of the Twin-Earth debate. I argued that the prospect of externalists doing so is slight. This suggests two possibilities, which I briefly explored.

The first one is to reject the Twin-Earth setting as adequate to think about the meanings of empty natural kind terms. For the setting only triggers clear and semantically relevant intuitions when the natural kind terms that are at issue are terms which refer to exemplified natural kinds which exist are salient - in the external physical environment of the speakers using those terms.

The other possibility for externalists is to endorse option (c), that empty natural kind terms are meaningless: meaninglessness is for them the price of reference-failure. Externalists have generally conceded to internalists that this is a bad option. But perhaps they should not make that concession 
and at least inquire into how far one can go with defending the claim that empty natural kind terms are meaningless. It would be a worthwhile thing to do. ${ }^{29}$

St Hugh's College, Oxford

${ }^{29}$ Thanks to Andrew Hudson and Åsa Wikforss for very helpful comments on a draft of this paper. I am also grateful to an audience in Barcelona at the BW6 - the Sixth Barcelona Workshop on Issues in the Theory of Reference, on Reference and Non-Existence. Thanks also to the referees for this journal for their very useful comments. 


\section{References}

Besson, C., 2010. Rigidity, Natural Kind Terms and Metasemantics, in The Semantics and Metaphysics of Natural Kinds, H. Beebee and N. Sabbarton-Leary (eds), New York: Routledge USA: $25-44$.

— 2009. Externalism, Internalism and Logical Truth, The Review of Symbolic Logic, 2: 1-29.

Boghossian, P., 1997. What the Externalist Can Know A Priori, repr. in and ref. to 1998. Knowing our Own Minds: Essays on Self-Knowledge, Smith, B. and McDonald, C. (eds), Oxford: Oxford University Press: 271-284.

Brown, J., 2004. Anti-Individualism and Knowledge, Cambridge, Mass.: MIT Press.

Burge, T., 1974. Truth and Singular Terms, repr. in and ref. to 2001. Philosophical Applications of Free Logic, Lambert, K. (ed.), Oxford: Oxford University Press: 189-204.

- 1979. 'Individualism and the Mental', in Peter French et al. (eds), Midwest Studies in Philosophy 4: Studies in Metaphysics, Minneapolis, Minn.: University of Minnesota Press: 72-121.

- 1982. Other Bodies, in Thought and Object, Woodfield (ed.), Oxford: Oxford University Press: 97-120.

— 1986. Individualism and Psychology, Philosophical Review, 95: 3-45.

Chomsky, N., 1995. Language and Nature, Mind, 104: 1-61.

Devitt, M. 2005. Rigid Application, Philosophical Studies 125: 139-165.

Evans, G., 1976. Semantic Structure and Logical Form, repr. in and ref. to 1985. Collected Papers, Oxford: Oxford University Press: 199-221.

— 1982. The Varieties of Reference, Oxford: Oxford University Press.

Goldberg, S., 2005. An Anti-Individualistic Semantics for "Empty" Natural Kind Terms, Grazer Philosophische Studien, 70: 147-168.

Häggqvist, S., \& Wikforss, Å., Externalism and A Posteriori Semantics, Erkenntnis, 67:373-386.

Kripke, S., 1972. Naming and Necessity, repr. in and ref. to 1980. Naming and Necessity: Oxford: Blackwell.

Kitcher, P. and Stanford, P. K., 2000. Refining the Causal Theory of Reference for Natural Kind Terms, Philosophical Studies, 97: 99-129.

Korman, D. 2006. What the Externalist Should Say about Dry-Earth, The Journal of Philosophy, vol. 103, 10: 503-519.

Koslicki, K. 1999. The Semantics of Mass Predicates, Noûs, 33: 46-91. 
Kripke, S., 1972. Naming and Necessity, repr. in and ref. to 1980. Naming and Necessity: Oxford: Blackwell.

LaPorte, J., 2006. Rigid designators for properties, Philosophical Studies, 130: 321-36.

Lewis, D., 1979. Attitudes De Dicto and De Se, repr. in and ref. to 1983. Philosophical Papers, Vol. I, Oxford: Oxford University Press: 133-156

— 1983, New Work for a Theory of Universals, Australian Journal of Philosophy, 61: 343-377.

— 1984, Putnam's Paradox, Australasian Journal of Philosophy, 62: 221-236.

Ludlow, P., 2003. Externalism, Logical Form, and Linguistic Intentions, in The Epistemology of Language, Barber, A. (ed.), Oxford: Oxford University Press: 399-414.

Martì, G., 2004. Rigidity and general terms, Proceedings of the Aristotelian Society, 104: 129-46.

McKinsey, M., 1991. Anti-Individualism and Privileged Access, Analysis 51: 9-16.

McLaughlin, B. \& Tye, M., 1998. Externalism, Twin Earth, and Self-Knowledge, in Knowing our Own Minds: Essays on Self-Knowledge, Smith, B. and McDonald, C. (eds), Oxford: Oxford University Press: 285-320.

Putnam, H., 1975. The Meaning of "Meaning”, repr. in and ref. to 1975. Mind, Language and Reality: Philosophical Papers, Vol. 2, Cambridge: Cambridge University Press: 215-271.

Sainsbury, M., 2001. Sense Without Reference, repr. in and ref. to Sainsbury, 2002. Departing From Frege: Essays in the Philosophy of Language, London: Routledge: 205-223.

Sawyer, S., 2003. Sufficient Absences, Analysis, 63: 202-208.

Segal, G., 2000. A Slim Book about Narrow Content, Cambridge, Mass.: MIT Press.

Soames, S., 2002. Beyond Rigidity: The Unfinished Agenda of Naming and Necessity. Oxford: Oxford University Press.

Stoneham, T., 1999. Boghossian on Empty Natural Kind Concepts, Proceedings of the Aristotelian Society, 99: 119-122. 